\title{
Coumestrol, Bisphenol-A, DDT, and TCDD Modulation of Interleukin-2 Expression in Activated CD+4 Jurkat T Cells
}

\author{
Kenneth Ndebele $^{1,2}$, Paul B. Tchounwou ${ }^{1}$, and Robert W. McMurray ${ }^{2 *}$ \\ ${ }^{1}$ Molecular Toxicology Research Laboratory, NIH- Center for Environmental Health, School of Science and Technology, \\ Jackson State University, 1400 Lynch Street, P.O. Box 18540, Jackson, Mississippi, USA. \\ Email: paul.b.tchounwou@jsums.edu \\ ${ }^{2}$ Rheumatology Section, G.V. (Sonny) Montgomery V.A. Hospital and Division of Rheumatology and Molecular \\ Immunology, Department of Medicine, University of Mississippi Medical Center, Jackson, Mississippi 39216, USA. \\ *Correspondence to Dr. Robert W. McMurray. Email: rmcmurray@ medicine.umsmed.edu
}

Received: 20 September 2003 / Accepted: 20 November 2003 / Published: 29 February 2004

\begin{abstract}
Endogenous estrogens are known to modulate several components of immune response, including interleukin-2 (IL-2) production. IL-2 is a cytokine that plays an important role in adaptive immune responses. These responses may be modulated by xenoestrogens such as coumestrol, bisphenol A (BPA), DDT, and TCDD. In this research, we examined the effects and potential mechanisms of action of these estrogenic compounds on IL-2 production in activated CD4+ Jurkat T cells. IL-2 production was analyzed by ELISA and Western Blot. At the transcriptional level, protein expression was examined by RT-PCR. Coumestrol, DDT and TCDD (but not BPA) significantly suppressed IL-2 production in activated CD4+ Jurkat T cells, at the transcriptional and translational levels. The transcriptional suppression of IL-2 was associated with decreased protein levels of NF- $\kappa \beta$, an important IL-2 positive transcription factor, without affecting the expression of $\mathrm{I} \kappa-\mathrm{B} \alpha$ protein expression, an important inhibitor of $\mathrm{NF}-\kappa \beta$ nuclear translocation. Although the direct mechanisms of xenoestrogens modulation of the immune system remain to be elucidated, coumestrol-, DDT- and TCDD-induced suppression of IL-2 may have ramifications for our understanding of the impact of xenoestrogens on health and disease.
\end{abstract}

Key words: Xenoestrogens, IL-2, transcription, Jurkat T cells

\section{Introduction}

Several investigations have shown that estrogens have direct effects on immune response through modulation of cytokine production, lymphocyte cell cycle distribution and transit, lymphoproliferation, and cell-mediated immune responses [1-15]. 17- $\beta$-estradiol, the most common endogenous estrogen, is an aromatized steroid hormone that binds to a cytosolic estrogen receptor (ER); this hormone-receptor complex serves as a gene transcription regulatory unit [16-18]. Recently, it has been shown that $17-\beta$-estradiol suppresses $T$ lymphocyte IL-2 production at the molecular level through suppression of mRNA transcription and NF-kB protein levels [19].

Derived from plant or synthetic sources, xenoestrogens are exogenous environmental compounds having the common property of exhibiting estrogenic effects on classic endocrine target organs, such as the uterus or breast [20-24]. While endocrinological effects of these compounds (ecohormones) have been widely studied and the focuses of scientific and societal debates [25-27], their immunotoxicological effects have not been thoroughly elucidated. Direct xenoestrogenic effects on 
T lymphoproliferation and apoptosis have recently been described [28], suggesting that xenoestrogens influence normal lymphocyte biology. In the current study, representative xenoestrogens from major categories phytoestrogens (coumestrol), plastic monomers (bisphenol A- BPA), herbicides/health waste incineration (TCDD), and pesticides (DDT) - were examined for their effects on Jurkat T cell IL-2 production and potential mechanisms by which modulation may occur.

\section{Materials and Methods}

\section{Chemicals and Reagents}

Coumestrol, bisphenol A - BPA, DDT, fetal calf serum, and phorbol-myristate acetate (PMA) were obtained from Sigma Chemical Co. (St. Louis, MO). 17$\beta$-estradiol was also obtained from Sigma, and used as a positive control. TCDD was obtained from Cambridge Technologies (Cambridge, MA). RPMI medium, phenolfree RPMI, and culture supplements were purchased from Gibco/BRL (Gaithersburg, MD).

In order to detect potentially significant differences in xenoestrogen effects on IL-2 production, in vitro concentrations of xenoestrogens were used in a range of $10^{-9}$ to $10^{-6} \mathrm{M}$, based on previous studies of $17-\beta$ estradiol required to show an effect in transformed T cell lines [19]. A23187 and antibodies for the IL-2 ELISA were obtained from Pharmingen (San Diego, CA). IL-2 RT-PCR primers were purchased from Promega (Madison, WI).

\section{Cell Culture}

The CD4+ Jurkat $\mathrm{T}$ cell line was obtained from American Type Culture Collection (Rockville, MD). After thorough washing, Jurkat T cells were cultured at a density of 1 x $10^{6}$ cells $/ \mathrm{ml}$ in phenol-free RPMI 1640 supplemented with $5 \%$ charcoal stripped (steroid free) FCS, $200 \quad \mathrm{mM}$ glutamine, and $1 \%$ penicillin/streptomycin. Cells were cultured in 24 well plates and activated with $500 \mathrm{nM} \mathrm{A} 23187$ and $50 \mathrm{ng} / \mathrm{ml}$ PMA. These concentrations were previously determined to stimulate maximal IL-2 production (data not shown). Culture supernatants were collected by centrifugation.

\section{IL-2 ELISA}

IL-2 protein concentrations in the supernatant of cell culture were determined by standard sandwich ELISA using antibodies and standards obtained from Pharmingen (San Diego, CA) according to manufacturer's instructions. Assays were performed as previously described [19] on neat and diluted samples in duplicate on 96 well plates. Absorbance was measured on a Bio-Rad spectrometer at $450 \mathrm{~nm}$, and IL-2 concentrations were determined by comparison to a standard curve.

\section{RNA Preparation and Analysis}

RT-PCR was performed as previously described [19]. Total cellular RNA from Jurkat T cells was obtained by guanidium isothiocyanate lysis and centrifugation through a $\mathrm{CsCl}_{2}$ cushion. Three million cells were plated at $0.5 \mathrm{M} / \mathrm{ml}$ in $65 \mathrm{~mm}$ tissue culture dishes and stimulated with hormones. At the designated time of harvest cells were transferred to a $4 \mathrm{ml}$ polypropylene tube, pelleted, washed twice in $1 \mathrm{X}$ PBS and lysed in $3 \mathrm{ml}$ guanidinium. Centrifugation was performed for $16 \mathrm{hrs}$ at 33,000 rpm. RNA was resuspended, precipitated and quantitated spectrophotometrically.

In some experiments, mRNA was harvested using a Fast Trak kit (InVitrogen, Carlsbad, CA) according to manufacturer's instructions. Aliquots of RNA were run on an ethidium stained gel to ensure good quality. Identical qualitative results were obtained with both forms mRNA and total cellular RNA. Reverse transcription (RT) of RNA was performed under standard conditions using equal $\mu \mathrm{g}$ input RNA from each condition.

The PCR reaction was performed under the following conditions in a 25 ul reaction: 30 cycles of denaturing $\left(94^{\circ} \mathrm{C}, 1 \mathrm{~min}\right)$, annealing $\left(60^{\circ} \mathrm{C}, 2 \mathrm{~min}\right)$ and extension $\left(72^{\circ} \mathrm{C}, 5 \mathrm{~min}\right)$. The reaction was performed in a Perkin Elmer DNA Thermal Cycler: 10 pmoles each primer, 200 (M dNTP, 1.25 U Taq, 1 X Taq reaction buffer (all Promega) as previously described [67]. PCR primers were specific for human IL-2. PCR reactions were optimized for annealing temperature and were performed at various cycle numbers to ensure that the result obtained was within linear range of the amplification curve. GAPDH was amplified from the same RT reaction as a control. Polaroid photos of ethidium stained gels are shown. The results are semi quantitative when performed in this fashion.

\section{Western Blot Analysis}

For Western analysis as previously described [19], 2 to $5 \times 10^{6}$ cells were cultured $\left(1.0 \times 10^{6} / \mathrm{ml}\right)$ and stimulated. Cells were harvested and pelleted in an Eppendorf microcentrifuge $\left(1,200 \mathrm{~g}, 5 \mathrm{~min}, 4^{0} \mathrm{C}\right)$, washed in $1 \mathrm{X}$ PBS and resuspended in a cell lysis buffer containing $20 \mathrm{mM}$ Tris $\mathrm{pH} 8.0,0.5 \%$ Nonidet P-40, 1 $\mathrm{mM}$ EDTA, $1 \mathrm{ug} / \mathrm{ml}$ leupeptin, $1 \mu \mathrm{g} / \mathrm{ml}$ pepstatin, $1 \mathrm{mM}$ dithiothreitol, $1 \mathrm{mM}$ PMSF and $0.1 \mathrm{M} \mathrm{NaCl}$ (all from Sigma). After $20 \mathrm{~min}$ of incubation at $4^{0} \mathrm{C}$, supernatants were prepared $\left(8,000 \mathrm{~g}, 5 \mathrm{~min}, 4^{0} \mathrm{C}\right)$ and total protein concentrations determined by the method of Bradford and Lowry using Bio-Rad Protein Assay reagents in a microtiter assay. Fifteen $\mu \mathrm{g}$ of total cellular protein was electrophoresed on a $12.5 \%$ SDS-PAGE gel, transferred to a polyvinylidine difluoride membrane (Amersham, Arlington Heights, IL) by electroblotting overnight (25 $\mathrm{mM}$ Tris $\mathrm{pH} 8.3,192 \mathrm{mM}$ glycine, 20\% methanol, $15 \mathrm{~V}$, $100 \mathrm{~mA}, 4^{\circ} \mathrm{C}$ ). Membranes were blocked with $10 \%$ electrophoresis grade biotin-depleted non-fat dry milk 
(BioRad) in $1 \mathrm{X}$ PBS (10 mM Tris $\mathrm{pH} 7.5,100 \mathrm{mM}$ $\mathrm{NaCl}, 0.1 \%$ Tween-20), rinsed in PBS, probed with monoclonal mouse anti-human NF-kB and IkB (Pharmingen) at 1:1000 and 1:500 dilutions, respectively, and washed 3 times in PBS. The secondary antibody was HRP-conjugated goat anti-mouse whole IgG used at 1:1000 (Transduction Laboratories, San Diego,CA).

All antibodies were diluted in $1 \%$ milk in TBS. Membranes were washed three times and detection was performed by enhanced chemiluminescence with an ECL reagent kit (using $0.06 \mathrm{ml} / \mathrm{cm}^{2}$ of reagent) and Hybond autoradiography film (both Amersham). Biotinylated standards were used for molecular weight determination and were detected with 1:3000 streptavidin-horseradish peroxidase (Amersham). This reagent was only used after initial detection with the secondary antibody (Transduction Laboratories) because it was found to alter the signal of some primary antibodies if used simultaneously. It also performed better than avidinhorseradish peroxidase (BioRad) provided with the biotinylated markers. Blots were stripped as per the manufacturer's instructions and probed up to three times with different primary antibodies. Incubations were performed at $37^{\circ} \mathrm{C}$ for $30 \mathrm{~min}$ or RT for $1 \mathrm{hr}$. A Bio-Rad GS670 densitometer was used to determine the relative band intensity.

\section{Statistical Analysis}

Statistical analysis was performed by one-way ANOVA for multiple samples or by Student $t$ testing with matched pairing if appropriate. Statistical significance was considered at $p<0.05$. Data were graphically presented as means \pm standard errors of the means.

\section{Results}

Coumestrol, TCDD, and DDT Suppression of $I L-2$ Production

The effects of coumestrol, BPA, TCDD, and DDT on the production of IL-2 were initially examined in Jurkat T cells activated with A23197/PMA for 48 hours. IL-2 was measured by ELISA as described in Materials and Methods. As shown in Figure 1, IL-2 concentrations were variably but significantly suppressed $(p<0.05)$ by $10^{-8} \mathrm{M}$ to $10^{-6} \mathrm{M}$ coumestrol, DDT and TCDD. Bisphenol A showed a trend towards suppression of IL-2 production that did not reach statistical significance. TCDD suppression of IL-2 production showed definite concentration dependence whereas coumestrol and DDT showed more of a threshold phenomenon at concentrations of $10^{-8} \mathrm{M}$ and $10^{-6} \mathrm{M}$, reaching a statistically significant suppression without obvious concentration dependence. Concentrations of xenoestrogens at $\leq 10^{-9} \mathrm{M}$ did not show statistically significant suppression of IL-2. 17- $\beta$-estradiol $\left(10^{-6} \mathrm{M}\right)$, known to suppress IL-2 production [7-9,19], was used as a positive control; non-activated cells (i.e., absent A23187, absent PMA, or both) or xenoestrogen-exposed cells without activation, did not produce detectable supernatant IL-2 (data not shown).

Coumestrol, BPA, TCDD, and DDT Suppression of IL-2 mRNA Transcripts

Since steroid hormones act as transcription factors $[17,18]$, it was postulated that xenoestrogens modulate IL-2 production through suppression of mRNA. Using qualitative reverse transcription polymerase chain reaction (RT-PCR), and estrogen as a positive control [19], coumestrol, BPA, TCDD and DDT $\left(10^{-6} \mathrm{M}\right)$ were shown to suppress IL-2 mRNA transcripts at 18 hours of exposure, as indicated in the representative experiment (Figure 2). Similar results were seen in two additional experiments. In comparison to the ELISA results, in which BPA trended towards IL-2 suppression but did not reach statistical significance, all of the selected xenoestrogens variably suppressed IL-2 mRNA transcripts as assessed by RT-PCR.

\section{Coumestrol, TCDD, and DDT Suppression of $N F-\kappa B$ Binding}

IL-2 transcription is dependent on the binding and cooperation of several positive regulatory transcription factors including NF-кB $[29,30]$. Coumestrol, TCDD, and DDT appeared to inhibit the transcription of IL-2 in Jurkat $\mathrm{T}$ lymphocytes through the suppression of nuclear transcription. While multiple transcription factors are involved in the regulation of IL-2 production, the initial focus was on xenoestrogenic modulation of $\mathrm{NF \kappa B}$ as being quantitatively more important in Jurkat $\mathrm{T}$ lymphocytes [29].

As shown in the representative experiment $(n=3)$, coumestrol, DDT and TCDD but not BPA, inhibited NF$\mathrm{kB}$ expression at $8 \mathrm{hrs}$ in activated Jurkat T cells at $10^{-6}$ $\mathrm{M}$, as determined by Western blotting (Figure 3). While coumestrol, TCDD and DDT exposure of Jurkat cells reduced nuclear $\mathrm{NF}-\kappa \mathrm{B}$ protein levels, these xenoestrogens had no effect on $\mathrm{I} \kappa \mathrm{B} \alpha$, the cytoplasmic inhibitor that binds $\mathrm{NF}-\kappa \mathrm{B}$ and prevents its translocation to the nucleus [31, 32].

As it can be seen in the representative results $(n=3$; Figure 3), coumestrol, DDT, bisphenol A and TCDD had no effect on I $\kappa-\mathrm{B}$ after $8 \mathrm{hrs}$ of exposure; compared to suppression of NF- $\kappa \mathrm{B}$ protein levels by coumestrol, TCDD, and DDT. Similar results were seen in two additional experiments (not shown). 


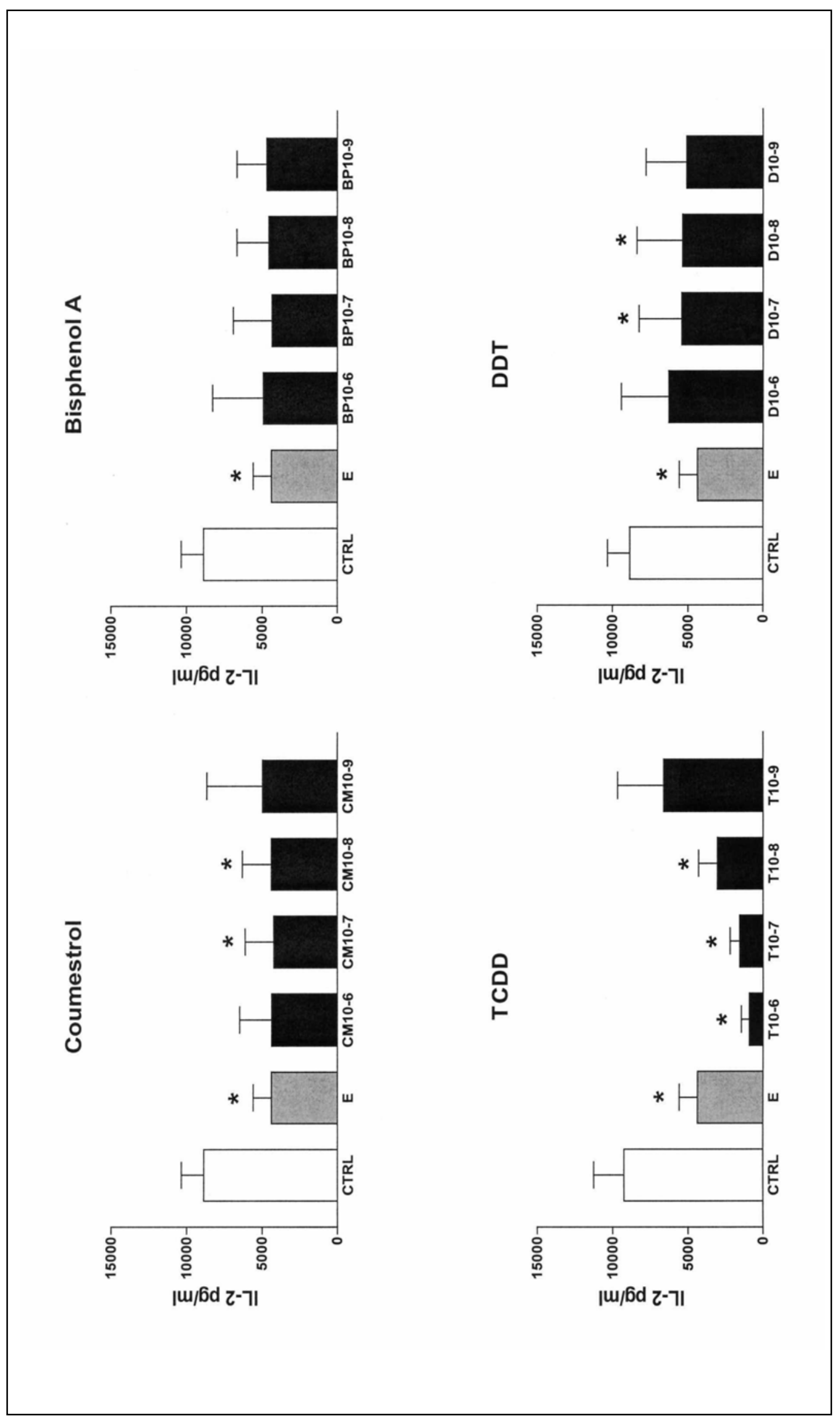

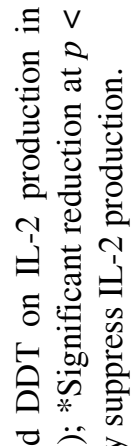

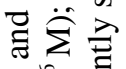

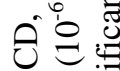
U 항 車苛 के 交希 어 i 空 पे 웅 बै ह ड़

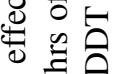
舟

ธี 苋骂 保它 空 $\rightarrow \stackrel{\Xi}{\circ}$ 选

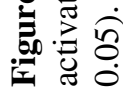




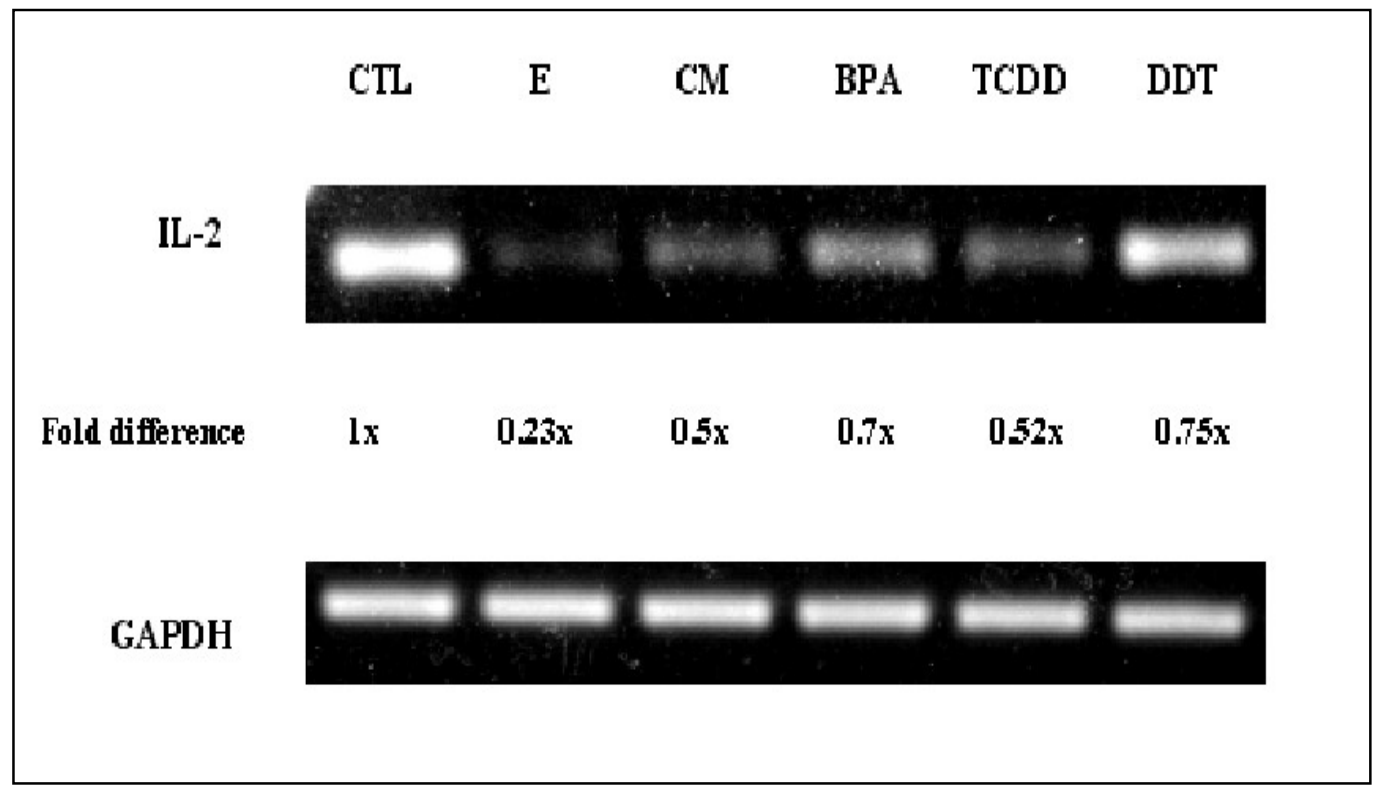

Figure 2. Semi quantitative RT-PCR of IL-2 mRNA transcripts from activated Jurkat T cells at $18 \mathrm{hrs}$ in control (C) vs. 17- $\beta$-estradiol, coumestrol, bisphenol A, TCDD, and DDT exposed cells $\left(10^{-6} \mathrm{M}\right)$. GAPDH is used as a housekeeping gene. One representative experiment $(n=3)$ is shown. MRNA transcripts were variably suppressed $(0.2-0.75 x$ of control) in 17- $\beta$-estradiol, coumestrol, BPA, TCDD, and DDT exposed Jurkat $\mathrm{T}$ cells compared to control $(1 \mathrm{x})$.

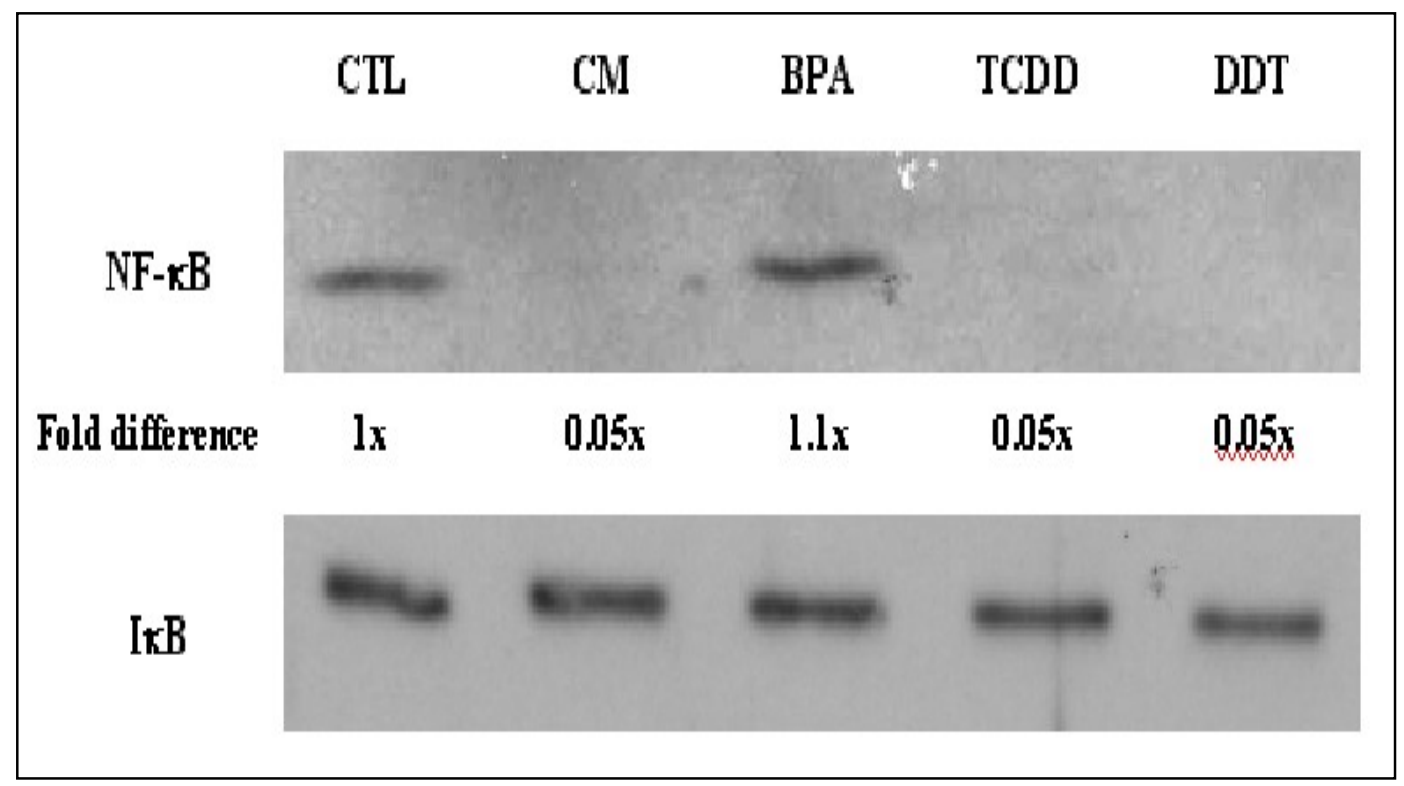

Figure 3. Western blot analysis of coumestrol, bisphenol A, TCDD and DDT effects on NF-kB in Jurkat T cell. Coumestrol, TCDD and DDT but not bisphenol A suppressed $(0.05 \mathrm{x}$ of control) NF-kB protein levels in Jurkat $\mathrm{T}$ cells as assessed by Western blotting at $8 \mathrm{hrs}\left(10^{-6} \mathrm{M}\right)$. Coumestrol, DDT, bisphenol A and TCDD induced had no effect on IkB protein in Jurkat T cells. Similar results were obtained in two additional experiments. 


\section{Discussion}

Xenoestrogens are environmental hormones (ecohormones) or compounds that exhibit estrogenic activity. They may interact with or disrupt endogenous estrogenic activity, and, as suggested by some investigations, may have implications for health and disease [20-27]. In the present study, coumestrol, TCDD, and DDT, but not bisphenol A, were shown to variably but significantly suppress IL-2 production in Jurkat CD4+ T cells. Bisphenol A did not achieve statistically significant suppression of IL-2, although there was a trend towards suppression. Coumestrol and DDT suppressed IL-2 at defined concentrations $\left(10^{-7} \mathrm{M}\right.$ and $\left.10^{-8} \mathrm{M}\right)$, whereas TCDD showed a clear concentration- dependent suppression of IL-2. The variability is likely due to xenoestrogenic potency with respect to estrogenic activity [21, 22], as well as possible differences in mechanisms of action [23-25]. IL-2 suppression appeared to occur at the level of transcription and was associated with inhibition of NF$\kappa \mathrm{B}$ by coumestrol, TCDD, and DDT. Discrepancies between IL-2 ELISA data (no statistically significant suppression for BPA), IL-2 mRNA transcript assessment (RT-PCR), and NF- $\mathrm{BB}$ protein levels (BPA not suppressed) are not completely unexpected. While having the common action of estrogen mimicry, they are unlikely to act (as discussed below) via identical mechanisms, and are likely to have pleiotropic effects that are time-, concentration-, and tissue-dependent. Nevertheless, our experimental data suggest that these specific xenoestrogens, at high concentrations, have specific effects on T lymphocyte IL-2 production and its transcriptional mechanisms.

IL-2 is an essential growth factor for T cells [29, 3336] and is important not only for $\mathrm{T}$ cell survival but impacts proliferation and differentiation of $\mathrm{T}$ cells into TH1 or TH2 predominance [35-38]. Inadequate IL-2 production may lead to $\mathrm{T}$ cell death or induction of clonal anergy [39,40], and deficient IL-2 production has been associated with autoimmune and inflammatory states [41,42]. Hence, the finding of xenoestrogenic modulation of IL-2 production may have ramifications for immunodeviation as well as manifestations of health or disease. Suppression of IL-2 production has been found in humans with xenoestrogen exposure [43]. Animal studies have shown that TCDD exposure is associated with suppressed IL-2 production and altered lymphocyte biology [44-46]. Coumestrol, a phytoestrogen, and DDT, a pesticide, appear to also share this property. Hence, further studies may be needed to confirm our results in lymphocytes. Jurkat $\mathrm{T}$ cells are useful models to examine transcriptional mechanisms of IL-2 production [33-35], as they share many IL-2 signaling characteristics of normal $\mathrm{T}$ cells [29-34].

While concentrations of xenoestrogens used in this study may exceed those detected in the environment and the general population, chronic, low level of exposure is known to have biological effects $[22,26,47]$. The purpose of this investigation was to identify possible mechanisms of immunomodulation and not necessarily establish environmental exposure-based cause-and-effect evidence. Furthermore, acute in vitro effects cannot be adequately extrapolated to chronic, low dose exposure in vivo effects, so results in the current study should be interpreted with utmost caution. Observed effects also occurred only in select xenoestrogens, implying that effects may be compound-specific and that broad generalization for individual compounds are not appropriate. As shown by the variability in degree of mRNA transcript or NF-kB protein levels, imunotoxicological effects are likely time-, concentration- or compound-specific, so that this preliminary study merely establishes the possibility that ecohormones may have an effect on IL-2 production and not that specific compounds used in this study have any direct relationship to effects on human health and disease. Nevertheless, xenoestrogens exhibit bioaccumulation such that immunomodulatory concentrations may be reached in exposed individuals over time; furthermore, these compounds may interact with each other or with endogenous estrogens, in either an additive, synergistic, or antagonistic manner [21, 23, 27].

Data in the current study suggest a direct suppressive effect of coumestrol, TCDD and DDT on NF-kB. Moreover, coumestrol, TCDD and DDT did not affect IkB protein levels in Jurkat T cells. Normally IkB sequesters NF-kB and prevents its translocation to the nucleus, thus preventing nuclear transcription, especially during the progression of the inflammatory cascade [3032]. While verification and extension of our results is needed, the changes induced in NF-kB by coumestrol, TCDD, and DDT suggests at least one of potentially several mechanisms, by which the transcription of IL-2 is suppressed in xenoestrogens-treated Jurkat $\mathrm{T}$ lymphocytes.

The effects observed in the current study may be estrogen receptor dependent or independent [48]. Jeon and Esser [49], in contrast to the findings of the current study, have shown that TCDD upregulated IL-2 promoter activity and IL-2 production through binding of the AHR to distal DNA IL-2 promoter motifs. However, xenoestrogens may also have AHR receptor independent effects on $\mathrm{T}$ lymphocytes [44] and xenoestrogen mechanisms of action are likely pleiotropic [50-52]. Delineating xenoestrogen-mediated effects through the ER or AHR is pivotal to understanding molecular mechanisms of xenoestrogens, but is beyond the scope of this initial study.

T-cell exposure to selective xenoestrogens at the time of activation may lead to variable, but less than optimal production of IL-2. Since the quality and quantity of an immune response may be determined by the quantity of IL-2 produced [35-40], coumestrol, TCDD and DDT may act as immunomodulators, and, in key situations requiring an IL-2 response, a primary 
immunosuppressant. While TCDD has been best studied and shown previously to suppress IL-2 production [45, 46], the current study expands the finding of IL-2 suppression to other xenoestrogens (coumestrol and DDT) and further demonstrates their effects on transcription and the transcription factor NF-KB, an important signal transducer for inflammatory signaling [32]. Not unexpectedly, xenoestrogen effects on IL-2 production are not uniform at equimolar concentrations, compatible with their structural and estrogenic potency heterogeneity [20-23]. Given the protean actions of NF$\mathrm{kB}[32,54]$, its suppression by coumestrol, TCDD, and DDT expands the possible influence of ecohormones on lymphocyte biology. Verification and expansion of current results is required; nevertheless, these data identify potential mechanisms by which accumulated ecohormones may influence immune or autoimmune responses.

Acknowledgments: This research was financially supported in part by a grant form the United States Environmental Protection Agency (\# U-91591701-0), and in part by a grant from the National Institutes of Health (\#1G12RR13459).

\section{References}

1. Whitacre, C. C.; Reingold, S. C.; O’Looney, P. A.; and the Task Force on Gender, Multiple Sclerosis and Autoimmunity. A gender gap in autoimmunity, Science 1999, 283, 1277-1278. Supplemental material online at www.sciencemag.org/feature/ data/983519.shl.

2. Olsen, N. J.; Kovacs, W. J. Gonadal steroids and immunity. Endocrine Rev. 1996, 17, 369-384.

3. Fox, H. S. 1995. Sex steroids and the immune system. Ciba Foundation Symposium 1995, 191, 203-211.

4. Ahmed, S. A.; Penhale, P. J.; Talal, N. Sex hormones, immune responses, and autoimmune diseases: Mechanisms of sex hormone action. Am. J. Pathol. 1978, 121, 531-551.

5. Giron-Gonzalex, J. A.; Moral, F. J.; Elvira, J.; Garcia, G. D.; Guerrero, F.; Gavilan, I.; Escobar, L. Consistent production of a higher TH1:TH2 cytokine ratio by stimulated $\mathrm{T}$ cells in men compared to women. Eur. J. Endocrinol. 2000, 143, 31-36.

6. Ahmed, S.A.; Dauphinee, M.J.; Talal, N. 1984. Effects of short-term administration of sex hormones on normal and autoimmune mice. $J$. Immunol. 1984, 134, 204-210.

7. Pung, O. J.; Tucker, A. N.; Vore, S. J.; Luster, M. I. Influence of Estrogen on Host Resistance: Increased Susceptibility of Mice to Listeria Monocytogenes Correlates with Depressed Production of Interleukin 2. Infect. Immunity 1985, 50, 91-96.

8. Elbourne, K.; Keisler, D.; McMurray, R. W. 1998. Differential effects of estrogen and prolactin on autoimmune disease in the NZB x NZW $F_{1}$ mouse model of systemic lupus erythematosus. Lupus 1998, 7, 420-427.

9. Pozsonyi, T.; Jakab, L.; Jakob, L.; Onody, K.; Cseh, K.; Kalabay, L. Effect of estrogen on the blast transformation of lymphocytes and interleukin 2 production in lupus erythematosus. Orv Hetil 1992, 133, 1167-1171.

10. Stein, B.; Yang, M. X. Repression of the Interleukin-6 Promoter by Estrogen Receptor Is

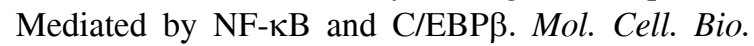
1995, 15[9], 4971-4979.

11. Ray, A.; Ray, P. Down modulation of interleukin 6 gene expression by 17B estradiol in the absence of high affinity DNA binding by the estrogen receptor. J. Biol. Chem. 1994, 269, 12940-12946.

12. Herrera, L. A.; Montero, R.; leon-Cazares, J. M.; Rojas, E.; Gonsebatt, M. E.; Ostroskyu-Wegman, P. 1992 Effects of progesterone and estradiol on the proliferation of phytohemagglutinin-stimulated human lymphocytes. Mutat. Res. 1992, 270, 211218.

13. Blagosklonny, M. V.; Neckers, L. M. 1994. Cytostatic and cytotoxic activity of sex steroids against human leukemia cell lines. Cancer Letters 1994, 76, 81-86.

14. Kincade, P. W.; Medina, K. L.; Smithson, G.. 1994. Sex hormones as negative regulators of lymphopoiesis. Immunol. Rev. 1994, 137, 119-149.

15. Athreya, B. H.; Pletcher, J.; Zulian, F.; Weiner, D.B.; Williams, W. V. 1993. Subset specific effects of sex hormones and pituitary gonadotropins on human lymphocyte proliferation in vitro. Clin. Immunol. Immunopathol. 1993, 66, 201-1211.

16. Wilson, J. D.; Foster, D. W. (eds.). Williams Textbook of Endocrinology 8th edition; Philadelphia, PA: WB Saunders Company, 1992.

17. Beato, M., et al. Gene regulation by hormones. Cell 1990, 56, 335-375.

18. Tsai, M.; O’Malley, B. W. 1994. Molecular mechanisms of action of steroid/thyroid receptor superfamily member. Аnnu. Rev. Biochem. 1994, 63, 451-486.

19. McMurray, R. W.; Ndebele, K.; Jenkins, J. 17- $\beta$ estradiol suppresses IL-2 and IL-2 receptor. Cytokine 2001, 14, 324-333.

20. Wolff, M. S. Environmental estrogens. Environ. Health Perspect. 1995, 103(9), 784-785.

21. Safe, S. H. Endocrine disrupters and human health-is there a problem? An update. Environ. Health Perspect. 2000, 108(6), 487-93.

22. Kaiser, J. Endocrine disrupters. Panel cautiously confirms low-dose effects. Science 2000, 290(5492), 695-697.

23. Neubert, D. Vulnerability of the endocrine system to xenobiotic influence. Reg. Toxicol. Pharmacol. 1997, 26, 9-29.

24. Ahmed, S. A.; Hissong, B. D.; Verthelyi, D.; Donner, K.; Becker, K.; Karpuzoglu-Sahin, E. 
Gender and risk of autoimmune diseases: possible role of estrogenic compounds. Environ. Health Perspect. 1999, 107(l 5), 681-686.

25. Crinnion, W. J. Environmental medicine, part one: the human burden of environmental toxins and their common health effects. Altern. Med. Rev. 2000, 5(1), 52-63.

26. Ashby, J. Testing for endocrine disruption postEDSTAC: extrapolation of low dose rodent effects to humans. Toxicol. Lett. 2001, 120(1-3), 233-242.

27. Ziegler, J. Environmental "endocrine disrupters" get a global look. J. Natl. Cancer Inst. 1997, 89(16), 1184-7.

28. Ndebele, K.; Tchounwou, P. B.; McMurray, R. W. Effects of xenoestrogens on $\mathrm{T}$ lymphocytes: Modulation of Bcl2, p53, and apoptosis. Int. J. Mol. Sci. 2003, 4, 45-61.

29. Hughes, C. W.; Pober, J. S. Transcriptional regulation of the interleukin-2 gene in normal human peripheral blood T cells. J. Biol. Chem. 1996, 271, 5369-5377.

30. Arima, N.; Kuziel, W. A.; Grdina, T. A.; Greene, W. C. 1992. IL-2 induced signal transduction involves the activation of nuclear NF-kappa B expression. $J$. Immunol. 1992, 149:83-91.

31. Whiteside, S. T.; Israel, A. I kappa B proteins: structure, function, and regulation. Semin. Cancer Biol. 1997, 8, 75-82.

32. Karin, M.; Delhase, M. The I kappa B kinase and NF-kB: key elements of proinflammatory signalling. Semin. Immunol. 2000, 12, 85-98.

33. Weiss, A.; Wiskocil, R.L.; Stobo, J. D. 1984. The role of T3 surface molecules in the activation of human T cells: A two-stimulus requirement for IL-2 production reflects events occurring at a pretranslational level. J. Immunol. 1984, 133, 123-128.

34. Landegren, U.; Andersson, J.; Wigzell, H. 1985. Analysis of human $\mathrm{T}$ lymphocyte activation in a $\mathrm{T}$ cell tumor model system. European J. Immunol. 1985, 15, 308-311.

35. Weiss, A., and Littman, D., R. 1994. Signal transduction by lymphocyte antigen receptors. Cell 1994, 76, 263-274.

36. Smith, K. Interleukin 2: inception, impact, implications. Science 1988, 240, 1169-1176

37. Mosmann, T. R.; Sad, S. 1996. The expanding universe of $\mathrm{T}$ cell subsets: Th1, Th2 and more, Immunol. Today 1996, 17, 138-146.

38. Scott, P. 1993. Selective differentiation of CD4+ T helper cell subsets. Curr. Opinion Immunol. 1993, 5, 391-397.

39. Schwartz, R. H. A cell culture model for $T$ lymphocyte clonal anergy. Science 1990, 13491356.

40. Go, C.; Miller, J. 1992. Differential induction of transcriptional factors that regulate the interleukin-2 gene during anergy induction and restimulation. $J$. Exp. Med. 1992, 175, 1327-1336.
41. Huang Y. P.; Perrin, L.; Miescher, P.; Zubler, R. H. 1988. Correlation of $\mathrm{T}$ and $\mathrm{B}$ cell activities in vitro and serum IL-2 levels in systemic lupus erythematosus. J. Immunol. 1992, 141, 827-833.

42. Schimpl A, Berberich I, Kneitz B, Kramer S, Santner-Nanan B, Wagner S, Wolf M, Hunig T. IL-2 and autoimmune disease. Cytokine Growth Factor Rev. 2002 Aug-Oct; 13(4-5): 369-78.

43. Daniel, V.; Huber, W.; Bauer, K.; Suesal, C.; Conradt, C.; Opelz, G. Associations of blood levels of PCB, HCHS, and HCB with numbers of lymphocyte subpopulations, in vitro lymphocyte response, plasma cytokine levels, and immunoglobulin autoantibodies. Environ. Health Perspect. 2001, 109(2), 173-178.

44. Hossain, A.; Tsuchiya, S.; Minegishi, M.; Osada, M.; Ikawa, S.; Tezuka, F. A.; Kaji, M.; Konno, T.; Watanabe, M.; Kikuchi, H. The Ah receptor is not involved in 2,3,7,8-tetrachlorodibenzo-p-dioxinmediated apoptosis in human leukemic $\mathrm{T}$ cell lines. J. Biol. Chem. 1998, 273(31), 19853-19858.

45. Nohara, K.; Fujimaki, H.; Tsukumo, S.; Inouye, K.; Sone, H.; Tohyama, C. Effects of 2,3,7,8tetrachlorodibenzo-p-dioxin (TCDD) on $\mathrm{T}$ cellderived cytokine production in ovalbumin (OVA)immunized C57B1/6 mice. Toxicology 2002, 172(1), 49-58.

46. Prell, R. A.; Dearstyne, E.; Steppan, L. G.; Vella, A. T.; Kerkvliet, N. I. CTL hyporesponsiveness induced by 2,3,7, 8-tetrachlorodibenzo-p-dioxin: role of cytokines and apoptosis. Toxicol. Appl. Pharmacol. 2000, 166(3), 214-221.

47. Ulrich, E. M.; Caperell-Grant, A.; Jung, S. H.; Hites, R. A.; Bigsby, R. M. Environmentally relevant xenoestrogen tissue concentrations correlated to biological responses in mice. Environ. Health Perspect. 2000, 108(10), 973-977.

48. Frigo, D. E.; Burow, M. E.; Mitchell, K. A.; Chiang, T. C.; McLachlan, J. A. DDT and its metabolites alter gene expression in human uterine cell lines through estrogen receptor-independent mechanisms. Environ. Health Perspect. 2002, 110(12), 1239-45.

49. Jeon, M. S.; Esser, C. The murine IL-2 promoter contains distal regulatory elements responsive to the Ah receptor, a member of the evolutionarily conserved bHLH-PAS transcription factor family. J. Immunol. 2000, 165(12), 6975-6983.

50. Kharat, I.; Saatcioglu, F. Antiestrogenic effects of 2,3,7,8-tetrachlorodibenzo-p-dioxin are mediated by direct transcriptional interference with the liganded estrogen receptor. Cross talk between aryl hydrocarbon- and estrogen-mediated signaling. $J$. Biol. Chem. 1996, 271(18), 10533-10537.

51. Umbreit, T. H.; Gallo, M. A. Physiological implications of estrogen receptor modulation by 2,3,7,8-tetrachlorodibenzo-p-dioxin. Toxicol. Lett. 1988, 42(1), 5-14.

52. DeVito, M. J.; Thomas, T.; Umbreit, T. H.; Gallo, 
M. A. Multi-site regulation of estrogen receptor by 2,3,7,8-tetrachlorodibenzo-p-dioxin. Prog. Clin. Biol. Res. 1992, 374, 321-336.

53. Silverstone, A. E.; Frazier, D. E. Jr.; Fiore, N. C.; Soults, J. A.; Gasiewicz, T. A. Dexamethasone, beta-estradiol, and 2,3,7,8-tetrachlorodibenzo-pdioxin elicit thymic atrophy through different cellular targets. Toxicol. Appl. Pharmacol. 1994, 126(2), 248-259.

54. Cerillo, G.; Rees, A.; Manchanda, Reilly, C.; Brogan, I.; White, A.; Needham, M. 1998. The oestrogen receptor regulates NF-kB and AP-1 activity in a cell specific manner. J. Steroid Biochem. 1998, 67, 9-88. 